\title{
Publicidades em revista digital: sua relação com a homepage e implicações para leitura
}

\author{
Jakeline de Melo Fenna ${ }^{\mathrm{i}}$ \\ Tania Pereira da Luz ${ }^{\text {ii }}$
}

\section{RESUMO}

A linguagem digital está presente no cotidiano de muitas pessoas em diversas situações. Por esta razão, muitos gêneros e suportes do meio impresso se deslocaram e/ou adaptaram-se ao ambiente virtual, entre eles, temos o suporte revista, com seus vários gêneros. Esta pesquisa trata das publicidades em duas revistas digitais em Língua Espanhola, sua relação com o gênero homepage e possíveis implicações na leitura. Como resultados, concluímos que a relação entre os dois gêneros analisados se dá de maneira diferente devido ao suporte em que estão inseridos. Variam, não só porque saem do meio impresso, mas, inclusive, dentro do ambiente digital. E, com isso, reforça-se a importância da leitura como uma atividade a ser ensinada, para que o leitor se torne proficiente no contato com os diversos gêneros que circulam em seu meio, tendo um posicionamento crítico e ativo no processo de compreensão leitora.

Palavras-chave: leitura; homepage; publicidade; suporte.

\begin{abstract}
The digital language is present in the daily lives of many people in different situations. For this reason, many genres and supports in printed media have moved and / or adapted to the virtual environment. Among them, we have the magazine support, with its various genres. This research deals with the publicity in two digital magazines in Spanish Language, its relationship with the homepage genre and possible implications in the reading process. As a result, we conclude that the relationship between the two analyzed genres occurs in different ways due to the support structure in which they are inserted. They vary not only because they leave the printed media, but also within the digital environment. Thereby, the importance of reading is reinforced as an activity to be taught, so that readers become proficient in their contact with the various genres that circulate in this environment, having a critical and active position in the process of reading comprehension.
\end{abstract}

Keywords: reading; homepage; publicity; support.

\footnotetext{
i Graduada em Letras Português/Espanhol pelo (Centro Universitário da Cidade-2005), Pós-graduada em Estudos da Linguagem na mesma universidade -2006. Especialista em Língua Espanhola Instrumental para Leitura (Universidade do Estado do Rio de Janeiro-2015/2016). Atualmente, cursa Mestrado na área de Estudos de Língua. Área de concentração: Linguística, na Universidade do Estado do Rio de Janeiro. https://orcid.org/0000-0002-8314-5584.| |jak.fenna@ hotmail.com

ii Graduada em Letras - Português/Espanhol pela Universidade do Estado do Rio de Janeiro (UERJ). Membro do projeto de pesquisa Interleituras e do Grupo de pesquisa Laboratório de Espanhol Virtual (GRPesq LabEV). Professora das séries iniciais do Ensino Fundamental na Secretaria Municipal de Educação do Rio de Janeiro e no Colégio Pedro II. | taninhasg @ hotmail.com
} 


\section{INTRODUÇÃO}

Considerando o advento das novas tecnologias de informação e comunicação (TICs), reconhecemos que novas formas de se comunicar suscitam uma inovação nas práticas sociais e vice-versa. Estamos cada vez mais imersos na tecnologia, numa sociedade que necessita de rapidez e agilidade na transmissão de informações. A linguagem digital está presente no cotidiano de todas as pessoas de diferentes idades, já que elas usam laptop, tablets, telefones celulares inteligentes e internet em diversas situações. Vemos que cada situação social dá origem a um gênero com características peculiares, mas que muitos gêneros e suportes do meio impresso se deslocaram e/ou se adaptaram ao ambiente virtual. Podemos destacar entre esses gêneros, o caso do suporte revista.

A revista digital suporta e faz circular vários gêneros textuais e dentre todos, destacamos a publicidade, que está presente tanto na revista impressa quanto na digital, embora assuma aspectos diferenciados em cada suporte. Percebemos que tem caráter argumentativo, mesmo que nem sempre assuma essa tipologia formalmente de modo rigoroso. Além disso, sua função comunicativa primária é vender; por isso, assumimos que sua leitura necessita atenção e criticidade. Essa descrição sumária do gênero nos chama atenção, em especial, para esta última característica: sua função. Devido a isso, o gênero publicitário é objeto de análise deste trabalho.

Propomos, com base neste tema, um estudo documental, de caráter exploratório e as seguintes perguntas de pesquisa: (a) considerando o gênero publicidade em revista digital e dada sua função de vender, como ela se relaciona, em termos de espaço e conteúdo, com a homepage do suporte? (b) que implicações podem estar associadas à sua leitura nesta relação entre os gêneros? Nosso objetivo geral, assim, é analisar como as publicidades se relacionam com a homepage na revista digital e que possíveis implicações podem causar na leitura.

Como sustentação teórica, consideramos os modelos de leitura e as estratégias utilizadas no processo leitor, a partir da visão sociointeracional de leitura, que reconhece o ato de ler como:

a capacidade de usar recursos linguísticos e extralinguísticos, que abrange sistemas diversos de conhecimentos e intervém, conjuntamente, na interpretação ou compreensão entendendo-se por compreensão o produto do processo de ler. (NUNES, 2005, p. 09) 


\title{
1 GENERO E PUBLICIDADE
}

É comum, para um leitor, saber reconhecer o que são notícias, anúncios, bulas de remédio, bilhetes, receitas culinárias, entre outros. Isso acontece porque "esses gêneros são conhecidos e reconhecidos tanto pela forma dos textos a eles pertencentes como pelos temas e funções que viabilizam e pelo estilo de linguagem que permitem" (BARBOSA; ROJO, 2015, p. 86). Sendo assim, é possível para um leitor reconhecer um soneto no texto, por sua forma - dois quartetos e dois tercetos -, mas o tema desse soneto só será compreendido a partir de seu estilo e dos sentidos que foram gerados no e a partir do texto.

Não precisamos conhecer todos os gêneros textuais, mas é preciso saber ler esses textos, conhecer suas finalidades, o recurso linguístico utilizado e que efeito de sentido pretende provocar (COSCARELLI, 2016). Afinal "embora o gênero seja relativamente estável, há alguns mecanismos composicionais e estilísticos para flexibilizá-lo e renoválo, sobretudo nas esferas criativas como as artes literárias ou musicais e a publicidade" (BARBOSA; ROJO, 2015, p. 104). No entanto, dominar um gênero favorece o seu melhor emprego e compreensão, conforme afirma Bakhtin:

Quanto melhor dominamos os gêneros tanto mais livremente os empregamos, tanto mais plena e nitidamente descobrimos neles a nossa individualidade (onde isso é possível e necessário), refletimos de modo mais flexível e sutil a situação singular da comunicação; em suma, realizamos de modo mais acabado o nosso livre projeto de discurso. (BAKHTIN, 2003, p. 285)

A partir dessas considerações teóricas e adotando uma orientação sociointeracional, nesse trabalho, assumimos o conceito de gênero como:

\begin{abstract}
textos que encontramos em nossa vida diária e que apresentam padrões sóciocomunicativos característicos definidos por composições funcionais, objetivos enunciativos e estilos concretamente realizados na integração de forças históricas, sociais, institucionais e técnicas. Em contraposição aos tipos, os gêneros são entidades empíricas em situações comunicativas e se expressam em designações diversas constituindo em princípio listagens abertas (MARCUSCHI, 2002, p. 96)
\end{abstract}

Variados têm sido os esforços na tentativa de se categorizar os gêneros, mas, como visto na citação anterior, as classificações são tão vastas que o mais importante não é listá-las. Conhecer critérios que determinam função, organização, estilo e saber 
utilizá-los a favor da compreensão e produção de textos, esse, sim, é o aspecto mais relevante e que envolve tanto aspectos sociais quanto cognitivos.

Com o advento das tecnologias informáticas e a expansão da internet, também ocorreram mudanças de hábitos e de comportamentos. Os consumidores passaram a cada vez mais utilizar a rede e, com isso, a publicidade tradicional teve que se adaptar a esse novo cenário. Atualmente, a publicidade na internet é vista como bastante promissora, movimentando bilhões de dólares no mundo e inovando-se continuamente (LOPES, 2014).

Vivemos, atualmente, em um contexto em que o consumo faz parte efetiva da vida das pessoas. Relações de consumo envolvem a sociedade, delineando os desejos dos indivíduos (BRAGAGLIA, 2018). Assim, a publicidade configura-se como a arte de despertar no público o desejo de compra, levando-o à ação (MALANGA, 1979). Como consequência, ela possui um papel de destaque, afinal determina comportamentos e induz necessidades, considerando a realidade econômica e cultural na qual está inserida.

Segundo Espinha (2014), estamos cotidianamente expostos a um bombardeio de mensagens, anúncios de todo tipo que saltam aos nossos olhos. Os meios de comunicação tornaram-se agentes que ditam normas fazendo-nos incorporar inconscientemente padrões de beleza e de comportamento. A publicidade, dessa forma, tem um papel indiscutível nesse processo de identificação, que nos deixa permeáveis à sua intencionalidade, evidente ou oculta, fazendo com que atinja a todos os grupos da sociedade.

Por lecionarmos em turmas de Ensino Médio, estamos constantemente em contato com jovens e adolescentes; desta maneira, nosso foco de interesse volta-se para essa faixa etária e, assim, concordamos com Espinha (2014) quando diz que:

\footnotetext{
Os jovens tornam-se evidentemente em alvos fáceis da publicidade tendo em conta que não têm ainda a sua identidade pessoal totalmente formada o que permite muitos conflitos e contradições neste processo de eleição da bagagem de valores que vão levar para a vida. (ESPINHA, 2014 p. 34)
}

Por isso, ao analisar as publicidades presentes em duas revistas, buscaremos implicações na leitura que possam oferecer possíveis caminhos de compreensão de forma crítica e consciente aos jovens que são o público-alvo de nosso trabalho. 


\title{
2 HOMEPAGE
}

A homepage - página inicial de um site - embora seja o primeiro gênero totalmente gerado pela web, reúne características parecidas com as de outros gêneros introdutórios impressos, como a primeira página de um jornal, já que ambas têm por objetivo traçar um panorama do conteúdo disponível para leitura, no ambiente virtual e/ou impresso (BEZERRA, 2007; DONATO, 2014). Existem, contudo, divergências em relação à sua classificação. Adotamos a classificação de Bezerra (2007) que considera a homepage um gênero introdutório, pois:

\begin{abstract}
Por gêneros introdutórios, em um sentido amplo, designo os gêneros textuais que, no corpo físico ou virtual de um determinado suporte, usualmente se agregam ao gênero ou gêneros principais como uma proposta de leitura prévia, em termos de orientação, síntese ou convite à leitura dos gêneros que são "introduzidos". (BEZERRA, 2007, p. 114)
\end{abstract}

Desta forma, estudos apontam para o fato de que a homepage executa duas funções principais: "Primeiro, ela introduz o usuário ao conteúdo geral do site [...] Segundo, funciona como a porta de entrada oficial para o website" (ASKEHAVE; NIELSEN, 2004, p. 9).

Quando o usuário está diante da homepage, tem diante de si uma apresentação do site e de todas as informações relevantes a ele, mas seu propósito não é apenas informativo. Seu modo de apresentação, sua aparência e seus recursos constituem a identidade visual do site (BEZERRA, 2007; SCHWINGEL, 2005). Este seria o conjunto de elementos gráficos que representam visualmente, e de forma sistematizada, um nome, uma ideia, produto, empresa, instituição ou serviço. Esse conjunto de elementos costuma ter como base a marca ou logomarca, ${ }^{1}$ - um símbolo gráfico e conjunto de cores (JORGE, 2017).

Dado o seu caráter tipicamente virtual, duas outras características da web também influenciam decisivamente a natureza dos textos mediados pela internet: a multimodalidade - recursos de sistemas semióticos diferentes na organização dos textos, como efeitos combinados, não isolados e o uso do hipertexto (BEZERRA, 2007).

\section{O SUPORTE REVISTA}


São do século XIX as primeiras notícias de revistas impressas no Brasil e a que ficou conhecida como a primeira revista impressa brasileira foi a Ensaios de Literatura, de 1812. Essas publicações não tinham caráter noticioso e, sim, se propunham a divulgar discursos, extratos de história antiga e moderna, viagens, trechos de autores clássicos, anedotas e pouco se assemelhavam à configuração dos suportes que temos hoje (ALI, 2015).

Quando o jornalismo chega às redes digitais, no final do século $\mathrm{XX}$, as revistas também se deslocam para esse mundo. Nesse movimento, transformam-se de tal maneira que sequer possuem uma denominação única. No Brasil, são chamadas de webrevistas, revistas digitais, revistas on-line, iMagazines, etc (NATANSOHN; GUEDES; BARROS, 2009; ALI, 2015).

A revista digital, como meio de comunicação periódico, reúne vários recursos, como a hipertextualidade, a multimodalidade e a interatividade, que a diferem de outros meios de comunicação, como rádio, TV, jornais e revistas impressas. Têm como objetivo proporcionar não a informação imediata do acontecimento, mas esclarecer os principais fatos que merecem o interesse do público (FREIRE, 2008). Ao utilizar todos os recursos disponíveis no meio virtual, a revista digital torna-se mais sofisticada no que tange à linguagem, ao estético e ao tecnológico, quando comparada ao suporte impresso (NATANSOHN et al., 2013).

No presente trabalho, segundo a proposta de Donato (2014, p. 43), consideramos a "revista digital um suporte, portador de textos escritos e multimodais, responsável pela fixação, apresentação, transporte e armazenamento dos gêneros materializados". Entendemos suporte, especificamente, como:

lócus físico ou virtual com formato específico que serve de base ou ambiente de fixação do gênero materializado como texto. Numa definição sumária, pode-se dizer que suporte de um gênero é uma superfície física em formato específico que suporta, fixa e mostra um texto. (MARCUSCHI, 2002, p. 11)

A revista digital é um suporte convencional que apresenta formatos variados. Além do formato dos sites em HTML (Hipertext Marcup Lamguage), podem utilizar formatos como Portable Document Format (PDF) e empregar softwares, como o Flash. Renovam-se constantemente, permitindo revistas mais multimidiáticas e interativas. Devido a tal variabilidade, ainda não se tem uma caracterização precisa do que é o ciberespaço da revista (TAVARES, 2013; NATANSOHN, 2013). O que sabemos é que as revistas digitais são publicações para computador, tablets e/ou outros dispositivos 
móveis, compatíveis com diferentes sistemas operacionais, que mesclam características das revistas impressas com as próprias do meio virtual. Sendo assim, têm periodicidade e não requerem uma atualização em tempo real.

Por último, sua segmentação permite atingir diversos públicos; têm portabilidade, já que são fáceis de manusear e carregar; possuem identidade gráfica, formadas por logos, capas e outros elementos gráficos e editoriais. Diferentemente do meio impresso, contudo, "apresentam um componente fundamental, a interatividade com as lexias de comunicação" (PAULINO, 2013, p. 93).

\section{LEITURA E O TEXTO DIGITAL}

Ao longo do tempo, foram postulados vários modelos descritivos de atividade leitora. O primeiro deles foi o ascendente, cuja ênfase cai no texto e o leitor é passivo. $\mathrm{O}$ seguinte, o descendente, tem a ênfase no leitor e considera sua atividade cognitiva. $\mathrm{O}$ terceiro modelo reúne as duas últimas perspectivas e considera que o processo é interativo, levando em consideração tanto o que o texto traz, quanto o que o leitor traz num processo de negociação.

Tratando a atividade leitora sob uma perspectiva sociointerativa (Nunes, 2005), Vergnano-Junger (2010) classifica o processamento da informação na compreensão leitora em duas categorias: unidirecional e multidirecional. Nelas, a autora enquadra os modelos tradicionais que descrevem a forma como a leitura ocorre.

$\mathrm{Na}$ primeira categoria, prevalecem os modelos: ascendente e descendente (KLEIMAN, 1996. SILVEIRA, 1998. VERGNANO-JUNGER, 2010). Na segunda, insere o modelo sociointeracional, no qual, ao realizar a leitura, "os diversos conhecimentos do leitor interagem em todo o momento com o que vem da página para chegar à compreensão" (KLEIMAN, 1996, p. 17).

Assumimos como base teórica nesse trabalho a perspectiva multidirecional de leitura (VERGNANO-JUNGER, 2016). Nela, o leitor desempenha um papel de reconstrutor de significados, utilizando vários recursos para atribuir sentidos ao texto. Entre estes recursos, por exemplo, temos seu conhecimento de mundo, sua bagagem de leitura, outros textos, o conteúdo do material lido, diferentes estratégias. Dessa forma, o leitor constrói, não apenas recebe o texto. Ao usar todas essas fontes de informação, ele 
trabalha com um processamento que assume diferentes caminhos e direções, interrelacionando cada dado; por isso, é multidirecional.

Cabe ressaltar que nos referimos, aqui, ao leitor proficiente, aquele que já superou a barreira de decifrar código e tem sua atenção voltada para a produção de sentido (TEIXEIRA, 2003). Essa tarefa não é uma característica inata, comum a todos os seres humanos, mas sim uma habilidade construída através de um longo processo de alfabetização e letramento (SOARES, 2004).

Uma questão importante a ser considerada é o texto em ambiente virtual. Este se torna muitas vezes um desafio para o leitor. Sua formatação e acesso podem causar impacto sobre a capacidade que tem um indivíduo de compreender aquilo que lê. $\mathrm{O}$ hipertexto digital pode ser entendido como "um texto exclusivamente virtual formado, na sua essência, por links".

O hipertexto, no ambiente virtual, oferece ao leitor acesso a uma quantidade quase ilimitada de outros textos, logo, "quando um link é acionado um salto é feito para o endereço ou página associado pela ligação, que pode ser uma palavra, frase ou nó do mesmo documento ou de outro endereço ou domínio" (BURGOS, 2006, p. 41). Isso confere ao leitor a responsabilidade de direcionar seu olhar, de traçar seu destino de leitura (SILVA, 2009).

Reconhecemos que ler é um ato de atribuir significados e construir sentidos, independentemente do meio ou do suporte (VIEIRA, 2007). Apesar disso, reconhecemos, também, que, ao ler um texto em ambiente virtual, o leitor "precisará conhecer/desenvolver nova(s) forma(s) de ler, reconhecendo as particularidades deste tipo de leitura" (VERGNANO-JUNGER, 2012, p. 193). Isso acontece, pois, ao ter um suporte diferente com recursos próprios, interagimos com ele de outra maneira. Os meios afetam nossa atitude tanto de leitura quanto de escrita, porque possuem características que permitem ou impedem certas coisas.

\section{OBJETIVO E METODOLOGIA}

Tendo em vista o cenário atual em que a internet trouxe consigo um grande avanço na comunicação humana e no qual temos acesso a uma infinidade de informações através dos mais variados gêneros textuais, como professoras de espanhol, 
avaliamos que essa inserção do mundo digital na comunicação cotidiana deve ser considerada e levada às práticas escolares. Isso também porque observamos, nos horários de intervalo, na entrada e saída da escola, o uso cada vez mais frequente da internet na faixa etária juvenil com acesso a diversos sites. Alguns destes podem ser as revistas, que oferecem diversidade de temática, de abordagens, com entretenimento, informação, produtos etc.

Um dos aspectos que nos chama a atenção nesse suporte (a revista) é o fato de que, em meio às suas muitas matérias, aparecem várias publicidades. Isso ocorre tanto no suporte impresso quanto no digital, com diferentes apresentações. Esse gênero - a publicidade - tem especial interesse devido ao seu caráter argumentativo e sua função comunicativa de vender. Sua leitura merece, portanto, preparo, inclusive para avaliar os aspectos éticos, econômicos e sociais que podem suscitar.

Nosso objetivo geral, portanto, é discutir a relação entre publicidades e a homepage presentes em duas revistas espanholas em sua versão digital e suas possíveis implicações na leitura. Ao introduzir-se entre (ou estar contígua a) uma reportagem numa determinada revista virtual, a publicidade abre possibilidades de caminhos para a compreensão leitora sobre o que nos interessa refletir. Tratando-se de uma revista em língua espanhola que será lida por jovens brasileiros, há ainda a questão da presença de publicidades em diferentes línguas conjuntamente, já que é comum, devido aos cookies $^{2}$, que apareçam também publicidades nacionais durante a navegação.

Percebemos, igualmente, que temas como moda, beleza, carros e motos, são comuns entre jovens alunos. Por isso, e por uma questão de recorte, estabelecemos para compor nossos corpora revistas em suporte digital, com essas temáticas, especificamente a homepage (página inicial, página principal ou página de entrada) das revistas e as publicidades que nelas aparecem. Acessamos, então, os sites das revistas www.elle.es e autobild.es para explorar o material.

Após a etapa de coleta e a análise de dados das revistas elle.es e autobild.es, percebemos que, em ambas as revistas, os menus possuíam alguns elementos de caráter genérico, como: "Notícias", "Reportagens", "Publicidades" e outros, de caráter temático, como: "Moda", "Beleza", "Passarela", "Vídeos" (elle.es) e "Tecnologia", "Carros", "Motos", "Fórmula 1" (autobild.es). Percebemos, então, que há uma mistura de categorias na homepage e que as escolhas para uma trajetória de leitura, 
provavelmente, dependeriam do foco de interesse do leitor, ou seja, num gênero específico ou numa temática.

Após observar as publicidades, descobrimos que elas se comportam de maneira diferente em relação ao formato - cores e letras, espaço na página e temática. Por isso, optamos por dividi-las em três grupos:

I. Publicidades oriundas de cookies;

II. Publicidades da homepage;

III. Publi-reportagens.

As publicidades oriundas de cookies estavam presentes apenas na homepage da autobild.es, ocupavam lugares distintos ao longo da página: ora no meio, na lateral, embaixo do menu, e não possuíam regularidade gráfica nem estética. Outra característica dessa publicidade é seu caráter opcional.

Percebemos esse "caráter opcional”, pois é possível que o leitor opte por fechar a publicidade. Fazendo isso, provavelmente haverá uma interrupção em sua leitura, pois, ao clicar para fechá-la, aparece outro banner - primeiro formato publicitário na $w e b$ - contendo informações para orientar o leitor a encerrar aquele anúncio. Somente depois de cumprir todos os comandos, o leitor poderá retomar a leitura da homepage.

Em relação ao segundo grupo de publicidades que encontramos em ambas as revistas, percebemos que, na verdade, elas não são publicidades, mas hiperlinks que irão direcionar o leitor à página publicitária. Observando atentamente o hiperlink, comprovamos que este possui somente um trecho do que será o conteúdo do gênero publicidade, assim como outros hiperlinks são trechos do que será uma reportagem, uma notícia etc., veiculadas na publicação. Logo, considerando que a homepage tem a função de apresentar o que a revista oferece de conteúdo, tanto pelas temáticas do menu quanto pelas temáticas dos rótulos, o leitor terá que clicar no hiperlink para ter acesso à publicidade.

Se o leitor for habituado ao suporte revista digital, não terá dificuldades em inferir que, ao clicar em determinado link, será remetido a uma página publicitária ou a uma reportagem, por exemplo. Ativará seus esquemas sobre o suporte, sobre os gêneros e suas respectivas características, orientando suas escolhas e sua trajetória. 
O último grupo de publicidades, as publi-reportagens, foram encontradas apenas na autobild.es. Trata-se de um gênero híbrido, que possui formato de reportagem, mas que sua função comunicativa, na verdade, é vender um produto. Ao se deparar com as estruturas de uma reportagem e clicar no hiperlink esperando ler uma reportagem, o leitor terá um desafio cognitivo ao iniciar a leitura e encontrar um texto publicitário, ou seja, ele vai ativar uma série de conhecimentos prévios e, quando chegar diante do texto, terá que avaliar esses conhecimentos ativados como inadequados e renegociar um novo esquema para poder (re)atribuir sentidos para o material lido.

\section{CONCLUSÃO}

Ao analisar as publicidades apresentadas nas revistas selecionadas, percebemos que nem sempre há correlação temática com o meio em que estão sendo veiculadas: a revista. Ademais, confirmamos que todas apresentaram uma característica comum: a persuasão. Por últimos, vimos que as publicidades variam de acordo com o suporte e o público ao qual se destinam.

Por isso, como resultado, concluímos que a relação entre os dois gêneros analisados se dá de maneira diferente devido ao suporte em que estão inseridos. Variam, não só porque saem do meio impresso, mas, inclusive, dentro do ambiente digital. Assim, consideramos que o estudo reforça a importância da leitura como uma atividade a ser ensinada. Tal processo de ensino-aprendizagem objetiva tornar o leitor proficiente no contato com os diversos gêneros que circulam em seu meio, tendo um posicionamento crítico e ativo no processo de compreensão leitora. No caso da publicidade, essa preocupação se acentua por seu caráter de estímulo ao consumo. As várias formas que assume precisam ser (re)conhecidas como esquemas recuperáveis que contribuam para essa avaliação consciente por parte do leitor.

\section{Referências}

ALI, Fatima. A arte de editar revistas: Um guia para jornalistas, diretores de redação, diretores de arte, editores e estudantes. Companhia Editora Nacional, 2015. 
ASKEHAVE, I.; NIELSEN, A. E. "Web-mediated genres": a challenge to traditional genre theory. In: Working Papers: Browse Journals \& Books n. 6, p. 1-50, 2004.

BAKHTIN, Mikhail. Estética da criação verbal. 4. ed. São Paulo: Martins Fontes, 2003.

BRAGAGLIA, Ana Paula. "Pertencimento e exclusão através do consumo e da publicidade//Belonging and exclusion through consumption and advertising". In: Contemporanea-Revista de Comunicação e Cultura, v. 16, n. 1, p. 311-332, 2018.

BEZERRA, B.G. Gêneros introdutórios mediados pela web: o caso da homepage. In: ARAÚJO, J.C. (Org). Internet \& ensino: novos gêneros, outros desafios. Rio de Janeiro: Lucerna, p. 113-125, 2007.

BURGOS, T.L. O hipertexto eletrônico de meio Ambiente: estratégias de leitura e navegação. 2006. Dissertação (Mestrado em Linguística Aplicada) - Universidade Federal do Rio Grande do Norte, Natal, 2006.

COSCARELLI, Carla Viana. Tecnologias para aprender. 1. ed. São Paulo: Parábola Editorial, 2016.

DONATO, A.B. "Gêneros textuais introdutórios e suporte: uma visão sociocognitiva da revista Nova Escola", 2014. Dissertação (Mestrado em Linguística) - Universidade do Rio de Janeiro, Instituto de Letras - 2014.

ESPINHA, Â.M.M.S. A utilização da publicidade em aula de Espanhol como língua estrangeira. Universidade de Coimbra, 2014. Disponível em https://estudogeral.sib.uc.pt/jspui/bitstream/10316/28264/1/Relat\%c3\%b3rio\%20de\%20 Est\%c3\%a1gio_\%c3\%82ngela_VF.pdf. Acesso: 05 out. 2015.

FREIRE FILHO, J; LEMOS, J.F. Imperativos de conduta juvenil no século XXI: a Geração Digital na mídia impressa brasileira. In: Comunicação, Mídia e Consumo, São Paulo v.5 n.13 p.11-25. 2008.

JORGE, Alana Giro. "Comunicação do governo federal e identidade brasileira: análise das logomarcas dos governos Lula e Dilma”. Signos do Consumo, v. 9, n. 1, p. 55-66, 2017.

KLEIMAN, A. Oficina de leitura: teoria e prática. Campinas: Pontes, 1996.

LOPES, B. Comunicação empresarial: transformações e tendências. Rio de Janeiro: Mauad X, 2014.

Disponível em:

https://books.google.com.br/books?id=mq4QBAAAQBAJ\&pg=PT100\&dq=formatos+ de+publicidade+na+internet\&hl=pt-

BR\&sa=X\&ved=0CE4Q6AEwBmoVChMI_qPf6NCuyAIVhx6QCh0K4wrB Acesso: 22 out. 2015. 
MALANGA, E. Publicidade: uma introdução. São Paulo: Atlas, 1979.

MARCUSCHI, Luiz Antônio et al. "Gêneros textuais: definição e funcionalidade". In: DIONÍSIO, Angela Paiva et al (org.). Gêneros textuais e ensino. Rio de Janeiro: Lucerna, v. 20, 2002.

NATANSOHN, G; GUEDES, C; BARROS, S. "Revistas online, redes sociais e leitura”. In: VII encontro nacional de pesquisadores em jornalismo, 2009, São Paulo. Anais. São Paulo, 2009.

NATANSOHN, G; GUEDES, C; BARROS, S. Jornalismo de revistas em redes digitais. Salvador: EDUFBA, 2013. Disponível em: http://labcomifp.ubi.pt/publicacoes/201501131549-jornalismo_de_revista_em_redes_digitais.pdf. Acesso: 15 set. 2015.

NUNES, Myriam Brito Corrêa. "Visão sócio-interacional de leitura." Oficina de leitura instrumental: planejamento e elaboração de materiais. Rio de Janeiro: IPEL/PUC-Rio, 2005 .

PAULINO, R.C.R. "Conteúdo digital interativo para tablets-iPad: uma forma híbrida de conteúdo digital”. In: Revista de Estudos da Comunicação. Curitiba, v.14, n.33, p.91106 jan./abr.2013.

ROJO, R. H. R.; BARBOSA, J. P. Hipermordenidade, multiletramentos e gêneros discursivos. São Paulo: Parábola Editorial, 2015.

SCHWINGEL, C. A. "Comunicação e Criação na Internet: a sistemática de trabalho das equipes de desenvolvimento web e dos grupos de desenvolvimento de softwares". In: XXVIII Congresso brasileiro de ciências da comunicação, 2005, Rio de Janeiro. Anais. Rio de Janeiro, Sociedade Brasileira de Estudos Interdisciplinares da Comunicação, 2005.

SILVA, A.P. Do texto ao hipertexto: um estudo de caso dos processos de leitura hipertextual de professores de educação a distância da UNITINS. Dissertação (Mestrado em Educação) - Universidade de Brasília, Brasília, 2009. Disponível em:

http://repositorio.unb.br/handle/10482/4821 Acesso: 07 de novembro de 2015.

SILVEIRA, R.C.P. "Leitura: produção interacional de conhecimentos". In: BASTOS, N.B. (Org). Língua Portuguesa. História, Perspectivas, Ensino. São Paulo. Educ - da PUC - São Paulo, 1998.

SOARES, M. "Letramento e alfabetização: as muitas facetas". In: Revista Brasileira de Educação, n. 25, p. 5-16, Jan/ Fev/ Mar/Abril de 2004.

TAVARES, F.M.B; SCHWAAB, R. A revista e seu jornalismo. Porto Alegre: Penso, 2013. 
TEIXEIRA, J.F. "Palestra proferida por ocasião do I Colóquio Leitura e Cognição. Universidade de Santa Cruz do Sul, 05/11/2003 (texto não publicado). Disponível em: https://online.unisc.br/seer/index.php/signo/article/viewFile/441/294. Acesso: 10 nov. 2015.

VERGNANO-JUNGER, C.S. "Elaboração de materiais para o ensino de espanhol como língua estrangeira com apoio da internet”. In: Calidoscópio. [S.1.]: Unisinos, v.8, n.1, p. 24-37, jan./abr. 2010.

VERGNANO-JUNGER, C.S. "Crise na leitura e formação de leitores: uma questão de política linguística?”. Matraga - Revista do Programa de Pós-Graduação em Letras da UERJ, v. 23, n. 38, 2016.

VIEIRA, I. L. "Leitura na Internet: Mudanças no perfil do leitor e desafios escolares". In: ARAÚJO, J. C. (Org). Internet \& ensino: novos gêneros, outros desafios. Rio de Janeiro, Lucerna, 2007, p. 244-267.

Recebido em: 20/06/2019

Aceito em: 03/07/2020

\footnotetext{
${ }^{1}$ Marca: um símbolo que representa uma identidade; logomarca: um símbolo associado à, uma ou mais palavras, que juntas, representam uma identidade.

2 Cookies: pequenos arquivos que os sites colocam no disco rígido de um computador quando um internauta os visita pela primeira vez.
} 